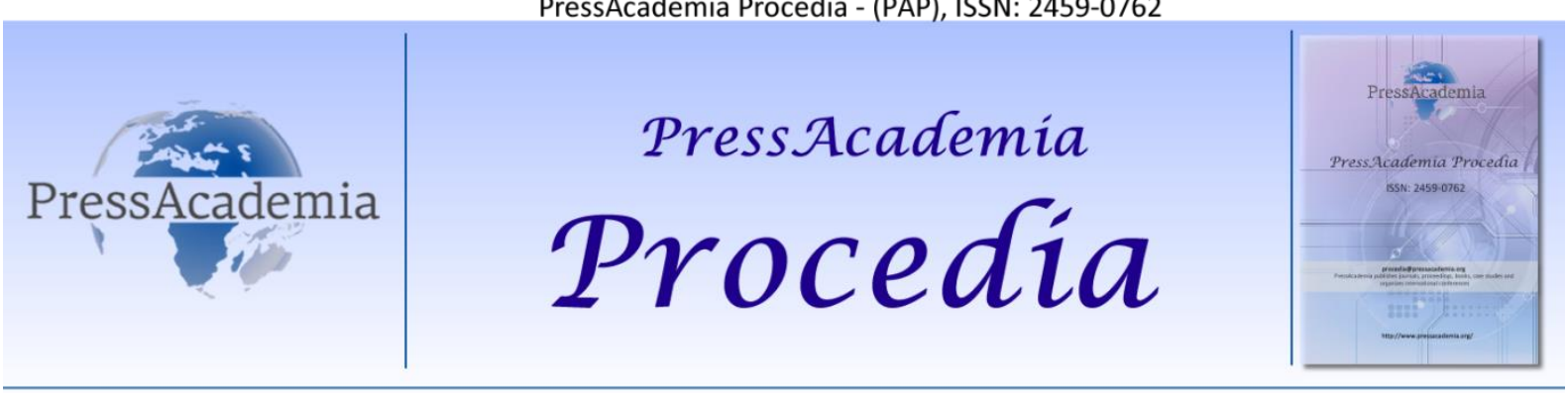

2nd World Conference on Technology, Innovation and Entrepreneurship

May 12-14, 2017, Istanbul, Turkey. Edited by Sefer Şener

\title{
DETERMINING SHIPBOARD INTEGRATION REQUIREMENTS Of MAINTENANCE 4.0 CONCEPT in MARINE ENGINEERING
}

\author{
DOI: 10.17261/Pressacademia.2017.568 \\ PAP-WCTIE-V.5-2017(6)-p.34-40
}

Cagatay Kandemir ${ }^{1}$, Metin Celik ${ }^{2}$

${ }^{1}$ Department of Marine Engineering, Istanbul Technical University. ckandemir@itu.edu.tr

2Department of Marine Engineering, Istanbul Technical University. celikmet@itu.edu.tr

\begin{abstract}
Ship machinery maintenance is a core technical aspect to achieve expected reliability, availability and efficiency in system level. Since maintenance practiceon-board ships is so critical, the integrity of planning, coordination and execution stages are expected to be well functioned. At this insight, this study considers the implementation potential of maintenance 4.0, relatively a new concept defined within industrial 4.0 initiative, in marine engineering field. In detail, the generic design and implementation requirements of maintenance 4.0 including key opportunities and challenges are identified. Moreover, a comprehensive requirement analysis is conducted to adopt maintenance 4.0 concept into ship machinery systems of existing and newbuilding merchant ships.
\end{abstract}

Keywords: Marine engineering, ship maintenance, maintenance 4.0, industry 4.0

\section{INTRODUCTION}

Maintenance is a necessary action for industrial organizations in order to retain and conserve organizational assets such as machinery, equipments, replaceable parts, hardwares and other devices. Any failure caused by poor maintenance policy is a threat to operational running of the planned work flow and schedule. On occasion, one of the system failures could lead extremely costful consequences depending on the business type and sectoral vulnerabilities. Besides, newly developed expensive processing systems are used in a widespread manner and companies increase their workforce on maintenance issues. For instance, in chemical industries $30 \%$ of the total workforce is assigned to the maintenance related departments (Jonge at al. 2017). Because of such reasons, maintenance strategy has an important role for organizations to achieve business goals by smooth and effective way. In the literature, there are various maintenance strategies which are often categorized in two groups as corrective maintenance (CM) and preventive maintenance (PM). It must be noted that the categorizing process is still under scrutiny by researchers in this field. CM is a maintenance activity which focuses on repairing or mending the failed part or equipment of a system. This process could be involved in more than one recovery approaches such as malfunction isolation, decomposition, replace, re-install, adjustment, verification and fix the relevant failed elements (Fang and Zhaodong, 2013). Therefore, malfunction time, detection and recovery time of a malfunction and the cost of malfunction could be considered for future operations. In run to failure (RTF) maintenance approach, the relevant part, equipment or machinery is simply allowed to breakdown. If the occurance of the problem begins to interfere system functionality, repairing \& replacement process is conducted (Piatrowski, 2001). This approach is recommended when operational shutdowns have no serious effect on productibility and equipment costs are not important.

Preventive Maintenance (PM) is a systematic inspection which focused on detecting a malfunction incipient failure. In general, time based maintenance schedule is planned to avoid unexpected shutdowns; therefore system availability is aimed to be maximized (Chalabia at al, 2016; Restrepo, Hennequin \& Aguezzoul, 2016; Hadidi, Al-Turki \& Rahim, 2012). Depending to the system characteristics, various modified PM applications have been studied, formulated or combined with other maintenance techniques in the literature. Despite these advantages of PM implementations, catastrophic failures are likely to occur and PM activities are usually criticized as labor intensive actions due to involvement of unneeded maintenance operations. In order to eliminate these disadvantages and enhancing the effectiveness of the processes, predictive maintenance (PDM) strategies have been applied in most of the industrial facilities. The PDM differs from PM by 
focusing on the actual condition of specified parts of a system notwithstanding a planned schedule. On that sense, regarding technical aspects and physical parameters such as vibration, pressure, flow, or voltage etc. must be monitored by responsible experts who involved in PDM implementations (Raza and Ulansky, 2016). Thus service life of equipments is aimed to be maximized while minimizing the unintended breakdowns and failure risk of system operation (Baidya and Gosh, 2015). In this context, condition based maintenance (CBM) approach come into prominence by many scientists as an effective PDM technique. At the present time, vibration analysis, acoustic emission, ultrasonic testing implementations, oil analysis, strain measurement, electrical effects, shock pulse method, radiographic inspection and thermographic monitoring technologies are utilized to have actual data interpretation in CBM (Marquez at al., 2012). According to obtained data, if the condition gets below of a specified system level, then repair or replacement process initiates after a controlled shutdown.

However, as "maintenance" concept addresses a vast of different fields in global industry; even the latest maintenance techniques could have some ambiguities for a specific system character. Hence, integration of all previously discussed maintenance approaches is utilized in order to have more effective operational results. For instance, reliability centered maintenance (RCM) proposes a combined maintenance approaches philosophy in concert with root cause analysis. Accordingly, RCM gives cause for a mathematical alghoritm or software program which focuses on specific failure modes most probably to occur (Yssaad, Khiat \& Chaker, 2012). If more than 20-25\%of maintenance workloadis based on breakdowns in an organization, RCM method could be beneficial to the overall process(Smith and Hitchcliffe, 2004).

With the emerging of new technologies such as remote diagnostic systems, e-maintenance concept has come to the forefront since 2000. E-maintenance provides an opening and gives wide coverage to information and communication technologies (ICT) for global companies who involved in competitive industrial activities in the world. Successful applications of e-maintenance strategy will bring benefits to the system reliability while integrating the costumers and suppliers with the aim of zero downtime performance (Han and Young, 2006). Even so, challenges of e-maintenance have been widely discussed regarding to aspects of human resource and training requirements, decision making process, difficulties when designing new business models and complexity of industrial adoption (Chowdhury at al., 2012).

Ever-growing technologic advancements on automation systems and data exchange became an opportunity to open a new door for even more futuristic maintenance concepts. Most of the industrial environments consider maintenance 4.0 as one of the most prudential subjects originated from "industry 4.0" theme. In the industry 4.0, the main idea is to achieve higher availability performance, reduced downtimes, optimized energy consumption and cut general maintenance costs by interoperability of machines supported with internet of things (IOT), internet of services (IoS) and internet of people (IoP) (Zezulka at al., 2016). Moreover, in addition of the cyber physical systems (CPS); equipments, sensors, machines, products, supply chain elements and customers get linked with each other thus a system's essential objects will share information in order to conduct control operations autonomously (Qin, Liu \& Grosvenor, 2016). So, the term of industry 4.0 have become the most popular subject among industry and academia, as result it has already dubbed as the fourth industrial revoulition with the expected marginal effect (Kagermann at al., 2013). In this industrial transformation, the maintenance 4.0 concept has an important role to contribute future's maintenance standard and it lies in the core of industry 4.0 due to requirements for new developed expensive systems, smart machines, autonomous devices and tools.

\section{LITERATURE REVIEW}

As industry 4.0 is still in the early stages of implementation, academia is discussed this phenomena and its key components in attempt to develop smart facilities of the future. CPS is the most used term in the industry 4.0 literature. According to Kagermann (2014), CPS is a combination of virtual environment and real life. Indeed, considering the underpinning aspects of industry 4.0, CPS has crucial importance due to potential benefits such as decentralizing system data. In contrast, case studies could be more explanatory to have more explicit understanding for both current challenges and potential handicaps. For instance, Stock and Seliger (2016) interrogate the industry 4.0 in the context of micro and macro perspectives in a case study for manufacturing a desktop tool. In this study, expected developments and opportunities elaboratively examined and findings demonstrated widely. They have created human-machine interaction through integrating CPS into their project and proposed a smart production factory model. Lee, Kao and Yang (2014) highlighted the importance of big data environment with the purpose of effective CPS implementations and in addition, a case study over Komatsu smart bulldozer has been demonstrated to have wide range of perspective on remote controlled self-maintenance availability in the scope of industry 4.0. Another case study on ongoing projects have been conducted by Carlos Toro et al. (2015) with the intent of establishing an architecture framework on knowledge based intelligent systems. That is because, delays of communication systems on given equipments cause an uncertainty, so reliable middlewares are needed if unpredicted situations desired to be eliminated. In addition to the previous studies, Bagheri at al. (2015) have designed an adaptive method between differently settled units and integrated this approach into their case study. Ivanov, Sokolov and Ivanova (2016) bring benefits to the CPS utilization with a mathematical alghoritm in order to establish smooth dynamic coordination of gathered data. In reference, any problem is aimed to be solved simultaneously by means of effective 
information system. Different angles of CPS integration into industry 4.0 is widely discussed in the literature; see also Albers at al. (2016), Landherr, Schneider \& Bauernhansl (2016), Kohlberg and Zuhlke (2015), Lee (2008), Wittenberg (2016), Dutra and Silva (2016), Monostori at al (2016), Garcia-walls at al (2017). As a general idea, there are various challenges to achieve for proper practice of CPS such as complexity, static and dynamic composition of sub-systems, processing big data, governance, general uncertainties and required employee consciousness. As a whole, challenges for the industry 4.0 concept are also particularly studied. To measure maturity level and readiness of manufacturing enterprises, Schumacher, Erol \& Sin (2016) submitted 9 dimensions and 62 assigned items and tested them in several companies for validation. The 9 dimensions such as strategy, leadership, customers, products, operations, culture, people, governance and technologymake possible a self assessment model of the organizations who attempt to be a part of industry 4.0 applications. Similarly, Thames and Schaefer (2016) noted that agility, flexibility and adaptability should be enhanced for actual development so, in this regard; they have suggested software architecture (software defined cloud manufacturing). As another scale, human adaptation is also under discussion by some scientists. Because, the general opinion; necessity to the human workforce is expected to diminish with the emerging of this concept. Nevertheless, new technologic developments will be in need of human contribution but from different aspects. In this sense, Erol at al (2016) put emphasys on the complexity and abstractness of the actual execution and discussed required competences for workers as another challenge to achieve. To eliminate this, they proposed a scenario based learning approach for different type of employee roles as manager, engineer and worker. Hecklau at al (2016) also highlighted the same challenge and they proposed required competences in their paper as comprehensive list of essential competences to support human resource management issue. In contrast, Blöch and Schneider (2016) also underlined training of workers and discussed a learning factory which conducts training practices by simulations. In order to train human workers properly; Quint, Sebastian and Gorecky (2015) proposed a system architecture for a mixed environment of CPS through augmented reality visulation techniques.

Eventually, in these studies; opportunies, challenges, benefits and potential impacts of industry 4.0 are thoroughly discussed. The concept of industry 4.0 and the term of maintenance 4.0 are very concentric with each other and as a consequence, in most of relevant studies; the term of "maintenance 4.0 "is not preferred by authors even if they contribute to the maintenance literature. However, examined papers in the literature review have broad information on both industry 4.0 and maintenance 4.0. In order to contribute to the literature; this paper discusses the shipboard integration requirements and challenges via "maintenance 4.0 " terminology.

\section{SHIP MAINTENANCE PROCESS}

A ship performing at sea has many complex aspects comparing with other industrial transportation units. Any breakdown could lead very costly consequences due to limited repair and recovery options while operating far from the land based service facilities such as shipyards, ports etc. In addition, unexpected downtimes and delays mean high amount of money loses for shipping companies so they could be verydifficult to compansate. At times, defects are not detected onboard ship until it is too late. Despite the current efforts on ship maintenance, machinery damage is still most common cause of ship incidents by $36 \%$ according to the Allianz Safety \& Shipping Review (2016). As ship maintenance process executed by few number of engineers, detailed checklists and everlasting machinery tasks must be followed anyhow in accord with planned maintenance system (PMS). PMS is widely used system which allows conducting maintenance operations in sync with the requirements of classification societies and other including parties such as shipyards. Because of the preventive maintenance (PM) nature of PMS, ship crew is responsible to fulfill PMS tasks properly at the right time. In this system, time based schedules and running hour based plannings allow ship operators to maintain equipments before exposing risks which may lead breakdowns. In other words, any machinery part already involved in PMS checklist has to be overhauled even if there is no predicted problem. Carried out tasks, PMS checklists and related documents are supervised by periodic inspections at the intervals in the scope of ISM Code (International Safety Management Code, Chapter 5, Section 10).

In addition to the PMS, corrective maintenance (CM) and run to failure (RTF) is also conducted in marine vessels at operational level. As mentioned previously, in RTF maintenance process is conducted only if a breakdown occures. Depending to the equipment type, existing spare parts or usable lifespan of an item; CM activities could be advantageous in some specific cases. However, CM and RTF most likely to cause major problems in the long term and as a matter of fact, it may lead more costly results such as ship disruption, expensive repair actions, port or class detentions, etc. For this reason, more reliable alternative ship maintenance methods have been analysed by researchers and followingly; condition based maintenance (CBM) has come forward thanks to technologic advancements in condition monitoring appliances recently.

CBM is still not a commonly using maintenance policy due to its additional requirements comparing with classical maintenances techniques but when it is done properly, operational efficiencies are expected to improve significantly. Maintenance costs and machinery failures could be reduced by means of instant monitoring of the critical system components. For existing ships, CBM is not preferred due to ship owners' unwillingness towards its actual integration thus newbuilding ships are considered as most likely candidates for this method. However, it is simpler to implement on new ships during their building period because required sensors, data networks and other technologic infrastructures can be 
easily integrated before entering service life. Although CBM pledges cost effective maintenance operations onboard, has some challenges as: breakdowns on technologic systems, missing or false monitoring due to sensor deterioration, competence requirements for ship operators and software based errors on data processing experiences.Apart from these maintenance approaches, reliability centered maintenance (RCM), e-maintenance and maintenance 4.0 applications have not been preferred notably in current shipping activities.

\section{REQUIREMENT OVERVIEWS}

Comparing with other systems, ship machinery is often larger, complex and difficult to operate so repairing process can be time-consuming, costly and can be even hazardous activities. Hence, PDM concepts such as maintenance 4.0 are crucial for ships in the sense of reducing downtime, financial loses and potential risks to human health. Since industy 4.0 is labelled as the fourth industrial revolution which is upcoming with highly expected major contributions into many industries, challenges are shown differences based on the types of industrial fields. In this point of view, requirements of maintenance 4.0 for maritime industry and potential challenges caused by industrial characteristics must be identified.

A ship's main engine system's critical elements generally consist of: pistons, injections, exhausts, valves, pipings and as the fundamental energy source; diesel oil, naturally. In order to obtain data from these parts of main engine for data process through IOT and cloud based software systems, new generation condition measurement units are required. Newly developed smart sensors are very capable for such duties as their functions are not limited with representing physical quantites, they are also able to receive, transmit, elaborate data and commands via digital channels (Fumagalli at al., 2010). For local data exchange of main engine system, radio-frequency identification (RFID) technology is suggested. RFID devices can support data exchange and also data storage automatically in a given local area, effectively. (Fumagalli at al., 2010). If RFID is not preferred, an loT based autonomous alternative data transferrable and storageable items should be used. In addition to the previous technology use, PLC (programmable logic controller) or infrared technologies could be chosen based on the failure modes.

Failure modes can be various for each system component in main engine. Selected failure modes for the given main engine parts are could be: Noise, vibration, temperature, oil leakages, unexpected suspendings for no reason, fail to start, structural deficiency, abnormal fluid viscosity and indicator malfunction. Obtained data from given equipments and failure mode types must be transmitted to integrated data acquisition and signal processing tool: Most widely used system is Supervisory Control \& Data Acquisition Systems (SCADA). By means of SCADA, elaborated information could be provided for the operating engineer (Fumagalli at al., 2010). In addition, system condition is monitored by engineering staff even if they are not on their working area by means of digital devices and synchronized network between human and machine (Campos at al., 2009). However, all obtained information must be gathered on a database to analyse, manage, redesign or reschedule the current maintenance operations. Cloud system which is supported with a big data and a decision making model is adviced at this stage. Even so, newly developed software based alghoritms and architectures in the scope of maintenance 4.0 may be proper alternatives in the future, as if they would be more effective. Wireless connection type (See also: Bluetooth, GSM, UMTS... etc) could be various thus it should be determined properly considering the whole preferred maintenance 4.0 items. Besides, connection with the shore, company head office, flag state administrations, port state controls or regional memorandums would be very beneficial to the merchant ship's overall conditions including maintenance and repairing issues. In the context of maintenance 4.0, augmented reality should also be implemented for use of ship crew.

In addition to the ship main engine and its components, a comprehensive maintenance 4.0 design should be implemented in ship's hull, steering gear systems, ballast water tank and fuel tank equipments, boiler and related systems etc. By synchronization of such local systems to the main database network, maintenance 4.0 requirements will be fulfilled. However, these arrangements are likely to face with many challenges for the near future.

Integrating maintenance 4.0 concept into newbuilding merchant ships are relatively easy comparing with the existing ships. Because, from the very beginning of their life cycle, ships could be designed conveniently with maintenance 4.0 concept. Besides, there could be a plenty of time for analyses and tests which are executed for probable failures. Existing ships have serious limitations for this application. Ship owners are usually reluctant to integrate new systems into their ships due to financial concerns. A maintenance 4.0 system's implementation process could take many days depending on ship characteristics. In addition, their complex and outworn structure will not allow for an easy modification processes. Moreover, there are various types of ships and also too many different sized ships. For this reason, software based failures are considered as one of the inevitable problems.

Additionally, for both newbuilding and existing ships; there are still several common challenges. Ships are operating under different environmental conditions so already recorded previous failure data may be not compatible for another ship. Another concern is national and international strict norms dictated by regulatory bodies such as international maritime organization (IMO), classification societies, flag state control, port state control etc. Any change that not recognized by 
these societies could not be permitted until new regulation is entried into force. If somehow, maintenance 4.0 succesfully applied to a ship's body; this new concept imposed extra workload to the already overburdened ship operators. Furthermore, ship operators must be trained for maintenance 4.0 specificly. However, they would not be eager for this new training program as they have been already attended for numerous certificate programs in order to earn their current job positions. Even if they have trained well, crew of a ship is changing frequenly and familiarization for a new ship's complex system is going to take a long time.

Despite the challenges, if mentioned problems are solved; ship operations become significantly efficient and maintenance based downtimes, breakdowns and failures are eliminated on a large scale. Likewise, incidents and potential risks sourced by maintenance operations are likely to diminish substantially. In the same way, maintenance operations of a ship may be inspected remotely with the networks that accessed to the cloud systems thus rigid prescriptive requirements of recognized bodies could be ameliorated. As result, fuel consumption of merchant ships becomes even lower due to conveniently maintained machinery system and followingly, more environmental friendly worldwide shipping services could be achieved.

\section{CONCLUSION}

This study discusses the implementation potential of maintenance 4.0 into marine engineering field. Firstly, maintenance methods CM, RTF, PM, PDM, RCM, e-maintenance and maintenance 4.0 are examined. Hence, technological requirements of maintenance 4.0 and industry 4.0 activities thoroughly analysed and presented for ships. Requirements are very dependent on type and characteristic features of a ship but in general, the most importantrequirements are:

- New generation condition measurement units : Smart sensors and RFID items.

- $\quad$ Based on the failure modes, PLC and infrared monitoring technologies may be needed.

- For signal processing tool, SCADA is required.

- $\quad$ CLOUD based system supported with big data or proper decision making approaches.

- Wireless connections such as Bluetooth, GSM or UMTS.

- $\quad$ Specialized failure mode sensors and data transfer units for engine room, ship hull, steering gear, ballast water system, fuel tanks and boiler systems.

Almost every field of global industry has some typical challenges for actual integration of the maintenance 4.0 concept. Identically, marine engineering has distinctive challenges as well as has typical opportunities. So, challenges and opportunities are identified via conducting a requirement analysis for onboard maintenance operations. Summarily, old ships have very little potential for the maintenance technique of fourth industrial revolution. Whilst newbuilding shipsmore likely to be a part of maintenance 4.0 but there are still serious challenges and uncertainties such as;

- $\quad$ Ships are operating in ever changing conditions

- There are numerous strict norms, classification societies and other organizations in maritime sector

- Crew is unskilled for such innovations and they are already overloaded

- $\quad$ Comprehensive specialized education programmes are required for ship engineers

- $\quad$ There are uncertainties in softwaring processes due to various ship types

- Unwillingnessof ship owners to the major innovative integrations

- Different ship characteristics will retard the know-how process from experienced ships

- Different ship characteristics make it difficult to manage for newly assigned ship operators to another system design.

\section{REFERENCES}

Albert A., B, Gladysz B., T, Pinner, V., Butenko, T., Stürmlinger (2016).Procedure for Defining the System of Objectives in the Initial Phase of an Industry 4.0 Project Focusing on Intelligent Quality Control Systems, Procedia CIRP, Volume 52, 2016, Pages 262-267, ISSN 2212-8271, http://dx.doi.org/10.1016/j.procir.2016.07.067.

Allianz Shipping Review (2016) Allianz 2016, http://www.agcs.allianz.com/assets/PDFs/Reports/AGCS Safety_Shipping Review_2016.pdf, date retrieved: 01.03 .2017 .

Baidya, R., \& Ghosh, S. K. (2015). Model for a predictive maintenance system effectiveness using the analytical hierarchy process as analytical tool. IFAC-PapersOnLine, 48(3), 1463-1468.

Bagheri, B., Yang, S., Kao, H. A., \& Lee, J. (2015). Cyber-physical Systems Architecture for Self-Aware Machines in Industry 4.0 Environment. IFAC-PapersOnLine, 48(3), 1622-1627.

Blöchl, S. J., \& Schneider, M. (2016). Simulation Game for Intelligent Production Logistics-The PuLL ${ }^{\circledR}$ Learning Factory. Procedia CIRP, 54, 130-135. 
Campos, Jaime, Erkki Jantunen, and Om Prakash. "A weband mobile device architecture for mobile emaintenance." The International Journal of Advanced Manufacturing Technology , 2009.

Carlos Toro et al. (2015)Procedia Computer Science 60 ( 2015 ) $362-370$

Chalabia,N. , M. Dahaneb, M., Beldjilalia, B., Nekic, A. (2016). Optimisation of preventive maintenance grouping strategy for multicomponent series systems: Particle swarm based approach. Computers \& Industrial Engineering. Volume 102, December 2016, Pages 440451

Chowdhury, Soumitra, Asif Akram, and Maria Åkesson. "E-maintenance as an emerging customer value generating it-enabled resource." 7th Mediterranean Conference on Information Systems, Guimarães, Portugal, September 8-10, 2012. 2012.

Dutra D. S., Silva, J. R. (2016). Product-Service Architecture (PSA): toward a Service Engineering perspective in Industry 4.0, IFACPapersOnLine, Volume 49, Issue 31, 2016, Pages 91-96, ISSN 2405-8963, http://dx.doi.org/10.1016/j.ifacol.2016.12.167.

Erol, S., Jäger, A., Hold, P., Ott, K., \& Sihn, W. (2016). Tangible Industry 4.0: a scenario-based approach to learning for the future of production. Procedia CIRP, 54, 13-18.

Fang, L.. Zhaodong, H. (2013). System Dynamics Based Simulation Approach on Corrective Maintenance Cost of Aviation Equipments. Procedia Engineering, Volume 99, 2015, Pages 150-155

Fumagalli, L., Di Leone, F., Jantunen, E., \& MacChi, M. (2010). Economic value of technologies in an e-Maintenance platform. IFAC Proceedings Volumes (IFAC-PapersOnline), 1(PART 1), 18-23. https://doi.org/http://dx.doi.org/10.3182/20100701-2-PT-4012.00005

García-Valls, M., Calva-Urrego, C., Alonso, A., \& de la Puente, J. A. (2016, April). Adjusting middleware knobs to suit CPS domains. In Proceedings of the 31st Annual ACM Symposium on Applied Computing (pp. 2027-2030). ACM.

Hadidi, A., Al-Turki, U, M., Rahim, U, A. (2012) Practical implications of managerial decisions to integrate production scheduling and maintenance, International Journal of System Assurance Engineering and Management, 224-230.

Han, T., Young, B. (2006). Development of an e-maintenance system integrating advancedtechniques. Computers in Industry, 57(6), pp. 569-580

Hecklau, F., Galeitzke, M., Flachs, S., \& Kohl, H. (2016). Holistic Approach for Human Resource Management in Industry 4.0. Procedia CIRP, 54, 1-6.

ISM, ISM code, chapter 5. Retrieved 28 December 2013

Ivanov, D., Dolgui, A., Sokolov, B., Werner, F., \& Ivanova, M. (2016). A dynamic model and an algorithm for short-term supply chain scheduling in the smart factory Industry 4.0. International Journal of Production Research, 54(2), 386-402.

Jonge, B., Teunter, R., Tinga, T. (2016) 30The influence of practical factors on the benefits of condition-based maintenance over time-based maintenance. Reliability Engineering \& System Safety, 2017 vol: 158 pp: 21

Kagermann, H. J. Helbig, A. Hellinger, W. Wahlster (2013). Recommendationsfor Implementing the Strategic Initiative INDUSTRIE 4.0: Securing theFuture of German Manufacturing Industry; Final Report of the Industrie 4.0 Working Group, Forschungsunion, 2013.

Kagermann, H. (2014). Chancen von Industrie 4.0 nutzen.Anwendung, Technologien und Migration, 603-614.

Kolberg, D., Zühlke, D. (2015). Lean Automation enabled by Industry 4.0 Technologies, IFAC-PapersOnLine, Volume 48, Issue 3, 2015, Pages 1870-1875, ISSN 2405-8963, http://dx.doi.org/10.1016/j.ifacol.2015.06.359.

Landherr. M, Schneider, U., Bauernhansl, T. (2016) The Application Center Industrie 4.0 - Industry-driven Manufacturing, Research and Development, Procedia CIRP, Volume 57, 2016, Pages 26-31, ISSN 2212-8271, http://dx.doi.org/10.1016/j.procir.2016.11.006.

Lee, E. A. (2008). Cyber Physical Systems: Design Challenges, 11th IEEE International Symposium on Object Oriented Real-Time Distributed Computing, pp 363-369.

Lee, J., Kao, H. A., \& Yang, S. (2014). Service innovation and smart analytics for industry 4.0 and big data environment. Procedia Cirp, 16, 38.

Marquez F.P.G, Tobias, A.M. and Perez, J.M.P. (2012). Condition monitoring of wind turbines: Techniques and methods, Mayorkinas Papaelias Renewable Energy, 46, 169-178.

Monostori, L., Kádár, B., Bauernhansl, T., Kondoh, S., Kumara, S., Reinhart, G., ... Ueda, K. (2016). Cyber-physical systems in manufacturing. CIRP Annals - Manufacturing Technology, 65(2), 621-641. https://doi.org/10.1016/j.cirp.2016.06.005

(http://www.sciencedirect.com/science/article/pii/S2212827114003497)

Piotrowski, J. April 2, 2001. Pro-Active Maintenance for Pumps, Archives, February 2001.

Qin, J., Liu, Y., Grosvenor, R. (2016) A Categorical Framework of Manufacturing for Industry 4.0 and Beyond, Procedia CIRP, Volume 52, 2016, Pages 173-178, ISSN 2212-8271, http://dx.doi.org/10.1016/j.procir.2016.08.005

Quint, F., Sebastian, K., \& Gorecky, D. (2015). A mixed-reality learning environment. Procedia Computer Science, 75, 43-48. 
Raza, A., Ulansky, V. (2016) Modelling of Predictive Maintenance for a Periodically Inspected System, DOI: 10.1016/j.procir.2016.09.032.

Restrepo L.M.R, Hennequin, S., Aguezzoul, A. (2016). Optimization of integrated preventive maintenance based on infinitesimal perturbation analysis. Comput. Ind. Eng. 98, C (August 2016), 470-482. DOI: http://dx.doi.org/10.1016/i.cie.2016.06.019

Schumacher, A. Erol, S. Sihn, W. (2016) A Maturity Model for Assessing Industry 4.0 Readiness and Maturity of Manufacturing Enterprises, Procedia CIRP, Volume 52, 2016, Pages 161-166, ISSN 2212-8271, http://dx.doi.org/10.1016/j.procir.2016.07.040.

Smith, Anthony M., and Glenn R. Hinchcliffe. 2004. RCM: gateway to world class maintenance. Amsterdam: Elsevier ButterworthHeinemann. http://www.123library.org/book details/?id=36146.

Stock, T., \& Seliger, G. (2016). Opportunities of Sustainable Manufacturing in Industry 4.0. Procedia CIRP, 40, 536-541. https://doi.org/10.1016/j.procir.2016.01.129

Thames, L., \& Schaefer, D. (2016). Software-defined Cloud Manufacturing for Industry 4.0. Procedia CIRP, 52, 12-17.

Wittenberg, C. (2016). Human-CPS Interaction - requirements and human-machine interaction methods for the Industry 4.0, IFACPapersOnLine, Volume 49, Issue 19, 2016, Pages 420-425, ISSN 2405-8963, http://dx.doi.org/10.1016/j.ifacol.2016.10.602

Yssaad, B., Khiat, M., \& Chaker, A. (2012). Maintenance Optimization for Equipment of Power Distribution System Based on FMECA Method. Journal Acta Electrotehnica, 53, 218-223.

Zezulka, F., Marcon, P., Vesely, I., \& Sajdl, O. (2016). Industry 4.0 - An Introduction in the phenomenon. IFAC-PapersOnLine, 49(25), 8-12. https://doi.org/10.1016/j.ifacol.2016.12.002 